\title{
Uma singular pragmática do escrever: um diário coletivo.
}

A singular pragmatics of writing: a collective journal.

Una pragmática única del escribir: un diario colectivo.

\section{Gislei Domingas Romanzini Lazzarotto}

Universidade Federal do Rio Grande do Sul, Porto Alegre, RS, Brasil.

Margarete Axt

Universidade Federal do Rio Grande do Sul, Porto Alegre, RS, Brasil.

\section{Resumo}

Este estudo aborda a formação em psicologia em contexto de intervenção num projeto de extensão acadêmica com jovens em medida socioeducativa e equipes que operam essa política pública. Esta demanda, enunciada na universidade através da extensão acadêmica, força um encontro entre a vida destes jovens e os modos de formar-praticar psicologia neste contexto. A problematização do processo de formação em psicologia nessas práticas é construída com os conceitos de experimentação, pragmática e enunciação, no diálogo com a esquizoanálise. Sob orientação da pesquisa-intervenção foi analisada uma ferramenta metodológica construída na experiência do grupo da psicologia nessas atividades, através de uma modalidade de escrita em ambiente à distância (lista de discussão) que constitui a proposta de diário coletivo. $\mathrm{O}$ estudo contribui na análise dos saberes pedagógicos e metodológicos, no uso deste tipo de ferramenta e nos modos de constituir a formação em ensino superior.

Palavras-chave: Formação psicologia, Diário coletivo, Experimentação, Pragmática.

\begin{abstract}
This study approaches psychology higher education in the context of an intervention in a higher academic extension project with youngsters fulfilling social-educative measure and the workers that operate in this public policy. This demand, enunciated at the university through the academic extension program, forces a meeting between the life of these youngsters and the process of forming and practicing psychology in this field. The questioning of the higher education psychology process in these practices is constructed with the concepts of experimentation, pragmatics and enunciation, in a dialogue with schizo-analysis. Upon orientation of the interventional research, a methodological tool was built upon the experience of the psychology work group on these activities. Through the use of a online writing environment (discussion lists), it was created a collective journal. This study contributes to
\end{abstract}


the analysis of pedagogical and methodological knowledge, the use of type of tool and in higher educational experience.

Keywords: Psychology Graduation, Collective Journal, Experimentation, Pragmatics

\section{Resumen}

Este estudio se ocupa de la formación en psicología en contexto de intervención en un proyecto de extension académica con jóvenes que cumplen medida socioeducativa y equipos que llevan a cabo esa política pública. Esa demanda, que se evidencia en la universidadpor la extensión académica, obliga a un encuentro entre las vidas de estos jóvenes y los modos de formar-practicar psicologia en ese contexto. La problematización del proceso de formación en psicología en estas prácticasse construye con los conceptos de experimentación, pragmática y enunciación, en el diálogo con el esquizoanálisis. Bajo la orientación de la investigaciónintervención se ha analisado una herramienta metodológica construída en la experiência del grupo de psicología en esas actividades, a través de un modo de escribir en un ambiente a la distancia (listas de correo) que constituye la propuesta de diário colectivo. El estudio contribuye en el análisis de los saberes pedagógicos y metodológicos, en la utilización de este tipo de herramienta y en los modos de constituir la formación en enseñanza superior.

Palabras clave: Formación en psicologia, Diario colectivo, Experimentación, Pragmática.

Apresentamos, neste estudo, o processo de criação de um Diário Coletivo no percurso de uma pragmática da escrita na experiência de formação em psicologia, em atividades que articulam o ensino e a pesquisa com a extensão acadêmica. As atividades de extensão, entre as quais emerge nossa pesquisa, tem como disparador a solicitação ao Departamento de Psicologia Social e Institucional, da Universidade Federal do Rio Grande do Sul da Universidade, para acompanhar programas de profissionalização e trabalho educativo para adolescentes em medida socioeducativa ${ }^{1}$. A análise dessa demanda da comunidade, no contexto de extensão, enuncia uma produção social contemporânea que força um encontro com os modos de viver juvenis, modos esses que escapam aos regimes prescritos pelos saberes pedagógicos e psicológicos, convocando docentes e estudantes a pensar outros modos de formar-praticar psicologia.

A formação em psicologia que vamos mapeando está conectada a uma diretriz das universidades públicas brasileiras, à medida que é desenvolvida 
nas relações acadêmicas com a comunidade, conjugando ensino e pesquisa com a extensão. Assim, falamos sobre um contexto do qual fazemos parte ao praticarmos o processo de formação em psicologia no exercício de relações com a comunidade. Nesse sentido, nossa preocupação está direcionada às práticas que contribuam na elaboração de metodologias de ensino superior que afirmem o caráter estratégico da extensão na formação e produção de conhecimento, visando a manutenção desta intervenção com a comunidade, em especial, no contexto de políticas públicas.

Considerando a noção de agenciamento proposta por Deleuze e Guattari (1997) vamos analisando os elementos que produzem essa experiência, pois assim evidenciamos as relações e as circunstâncias que tornam possível construir estes modos de formar e pesquisar. A estratégia pedagógica dos programas que constituem o contexto de nossas atividades de extensão envolve a oferta de formas de preparação para o trabalho articuladas a possibilidade de relações de convivência e pertencimento num espaço organizacional, através da interação de jovens com servidores públicos em seus contextos de trabalho. As organizações estatais constituem esse espaço educativo no seu ambiente de trabalho e criam um contraponto em relação as expectativas com esses jovens, as quais são centradas de forma hegemônica na vigilância, no perigo e na violência (Coimbra, 2001). De certa forma, esses programas se produzem num "nãolugar", tanto pelo fato de serem efetivados para além da função social prevista nestas organizações, como pelo modo como os trabalhadores destes locais passam a sustentar essa outra possibilidade de se relacionar com o público juvenil atendido em medidas socioeducativa e de proteção. Conforme afirmam Deleuze Guattari (1997), um agenciamento de enunciação molecular que não se explica apenas pelas razões presentes nas normas, e também não depende apenas de determinações sociais aparentes, pois reúne vários regimes de signos heterogêneos, portanto uma enunciação coletiva.

$\mathrm{Na}$ atualidade brasileira, os olhares silenciosos do medo e do nãopertencimento pousam nas relações com jovens, evidenciando um regime de visibilidade que diz respeito ao modo de objetivar e subjetivar a produção social da violência nestes corpos. $\mathrm{O}$ pouso toma forma na expressão de um modo juvenil configurado na infração e no abandono que vai sendo marcado nas situações de envolvimento com tráfico, o uso droga, a vida na rua, o fracasso escolar, os impasses 
nas relações de cuidado familiar, entre outras manifestações. No trabalho da extensão vamos convivendo com a multiplicidade juvenil e os modos de estudar, adoecer, infringir, sofrer, trabalhar, enunciando vidas que acontecem na trama de saberes-poderes em que psicologia e pedagogia se fazem praticar. Esse encontro com as demandas juvenis cria interrogações sobre como a psicologia intervém e, ao problematizarmos como os saberes psicológico e pedagógico objetivam as vidas juvenis, movimentamos também os modos de objetivar e subjetivar em docentes e estudantes. As questões proliferam e indagam: formar, praticar, pesquisar para quê?

O desenvolvimento do trabalho no grupo da psicologia, formado pela professora e estudantes que realizam a extensão acadêmica, vai evidenciando a presença da escrita como um modo de acolher a produção em curso nesta experiência. Entre as atividades de supervisão, seminário, leituras e discussões, o escrever numa lista de discussão acontece tanto na imediatez de fazer algo com o vivido após o trabalho com equipes e jovens, como no decorrer de qualquer hora do dia ou da noite em que o pensamento insiste. Ao invés de ficarmos sós com nossas perguntas e experiências, ou nos remetermos somente a um diário de campo individual, ou ainda, a um arquivo solitário no computador que aguarda o dia da reunião presencial, o caminho é marcado pelo insistente acesso a uma lista de discussão (ferramenta de comunicação a distância). Vamos percebendo que este uso cada vez tem menos a função de registrar e de comunicar os fatos ocorridos ou os eventos previstos; e passamos a discutir de que se tratava essa modalidade de escrita. Nessas circunstâncias formulamos as seguintes questões para orientar nosso estudo: Como a ferramenta lista de discussão se acopla ao processo de formação em psicologia e passa a compor um modo de escrever no movimento de um encontro com as políticas juvenis que força-afeta a enunciação de formar-praticar psicologia? De que se trata esse contágio que percorre o movimento da prática de formação em extensão para uma escrita, de uma escrita para uma lista de discussão, de uma lista de discussão para um modo de escrever nomeado diário coletivo? Considerando essas questões apresentamos os três movimentos que constituem o estudo desta singular pragmática do escrever.

\section{Movimento I - A experimentação de uma lista de discussão}

Uma lista de discussão é formada 
por um grupo de pessoas que utiliza a comunicação mediada por computador em internet através do correio eletrônico via endereços (e-mail) de seus participantes e envio de mensagens com a utilização de texto escrito digitalizado. Os grupos de discussão, também denominados listas de discussão, têm como característica a distribuição de cada mensagem enviada para todos os integrantes da lista de endereços inscrita no grupo. $\mathrm{O}$ acesso pode ser restrito aos inscritos, sendo que um de seus integrantes assume a função de moderador para criá-la. Este serviço de grupo de discussão é oferecido, gratuitamente, por provedores de internet, incluindo um website, comum aos participantes do grupo, que mantém o registro de todas as mensagens enviadas e respectivos arquivos anexados.

A opção pelo uso de uma lista de discussão em nosso grupo de extensão e não de outros ambientes a distância, vinculou-se à facilidade de acesso, ao domínio da ferramenta pelos seus integrantes e à rapidez do recebimento de mensagens. Inicialmente, a "escolha" da mesma teve um caráter eminentemente instrumental para manter a comunicação de agenda e combinações de atividades entre os membros do grupo, pois não tínhamos a noção de que o uso desta ferramenta poderia compor a problematização da prática da psicologia.

No decorrer das atividades, o grupo da psicologia participante do projeto de extensão passa a utilizar a lista de discussão para relatos das práticas, conforme demanda de quem vive essa experiência ou por solicitação de alguém deste grupo que quer saber sobre os acontecimentos do trabalho. Não há uma combinação de que tudo deve ser escrito na lista, nem uma forma definida de como escrever. O que vai acontecendo é uma escrita no tom da fala, de quem conta a alguém o que vive, tanto no que se refere ao relato de atividades, como de idéias, perguntas, dúvidas, incômodos gerados no percurso deste fazer-viver. A escrita também acontece de forma "misturada" com citações teóricas ou comentários de autores, indicações de leituras relacionadas ao que se está trabalhando. Os projetos de trabalho, o planejamento de atividades, os relatórios e os materiais enviados pelas equipes de organizações com quem se trabalha, também são elementos que vão dando forma à matéria que constitui a "lista".

No movimento de trocar mensagens a respeito da intervenção nas atividades de extensão, a interação entre participantes do grupo passa a delimitar menos as posições de quem escreve, e mais o movimento de escrever e compartilhar a experiência em 
sua multiplicidade. A conexão em rede com a matéria escrita de acesso permanente possibilita o contato em qualquer tempo com o que está sendo produzido-escrito. O grupo de trabalho da psicologia se forma por estar na universidade, mas para estar fora dela e assim mantém com a lista um "lugar" de permanente acesso, que vai sendo constituído neste "espaço mútuo", feito das grafias no fluxo da experiência e do pensamento. Essa "pedagogia a distância", aparentemente sem lugar e em todos os lugares, evidencia uma problematização dos modos de formar que passa do uso do espaço como marca do tempo de aprender, para aprender no tempo e na coexistência de movimentos entre espaços.

Portanto, fomos percebendo que não tínhamos apenas uma lista de discussão, mas uma pragmática própria de um modo de escrever na formação em psicologia que se faz na ressonância da experiência vivida em atividades de extensão.

Axt (2005), destaca que as ferramentas de comunicação a distância podem sustentar sua estrutura num complexo conceitual que busca privilegiar o acesso ao ambiente de modo mais intuitivo, mantendo o usuário imerso no texto e contexto de intervenções, ao mesmo tempo em que ele se dedica a produzir seu próprio texto nesta experiência. A autora destaca a perspectiva de uma interação dialógica (argumentativa, narrativa, expressiva, contratual), de caráter teórico conceitual-metodológico, em que todos os participantes podem se colocar em posição de interlocução, por meio de uma escrita autoral. Mutti e Axt (2008) destacam a importância de observarmos em nossas ações pedagógicas os princípios metodológicos da dinâmica destes novos ambientes de aprendizagem com as ferramentas da tecnologia a distância. No estudo de experiências desta natureza, em ensino superior, Axt et cols. (2003) afirmam que as tecnologias digitais, dentre elas os ambientes a distância, detém especificidades que podem ser agenciadas de diferentes modos e, assim, produzir processos de subjetivação voltados à criação de sentidos diferenciados e à construção autoral de uma rede de conceitos. Esses trabalhos inscrevem-se no plano das aprendizagens, das relações éticas, da expressão estética e da produção de sentido, problematizando processos de investigação da invenção.

Nesta interlocução conceitual e metodológica para problematizar nossa experiência associamos os modos de inventar à noção de experimentação apresentada por Gilles Deleuze. O autor considera como ponto de partida da 
experimentação a contingência de um encontro que instala "a necessidade absoluta de um ato de pensar, de uma paixão de pensar.” (2000, p. 240). Trata-se de ultrapassar o que se coloca como limite entre o sujeito e o objeto, para problematizar a relação produzida no movimento que força o encontro, princípio que orienta a pesquisa intervenção (Aguiar; Rocha, 2007). Portanto, para experimentar, não basta entregar-se à experiência, é preciso construir um modo de permanecer no processo em curso que solicita invenção, o que implica em construir um modo de intervir que acolha a experiência e seus movimentos com a multiplicidade que nos constitui em cada peculiar modo de intervenção. $O$ que promove essa demanda por experimentar? A diferença. Conforme Deleuze (2000) é a diferença que invade $\mathrm{o}$ pensamento quando a representação não dá conta de responder ao que acontece, e nos leva a criar outros modos de pensar, pesquisar, intervir.

Quando problematizamos a experiência num plano conceitual orientado pela experimentação, movimentamos tendências de uma pedagogia e de uma psicologia que forçam novas formas de enunciação. Não saber o que fazer diante das demandas produzidas no encontro com as políticas juvenis e ensinar com a matéria que se faz desta problematização, são condições que promovem singulares formas de expressão. É neste agenciamento que a lista de discussão torna-se um território de acolhimento de matérias de expressão que constroem o movimento da escrita e que passa a constituir um Diário Coletivo. Mas do que se trata um diário no âmbito destas práticas de formação em psicologia?

\section{Movimento II - Um diário que dedilha forças e subjetividade.}

A escolha por pensar os movimentos da escrita nas práticas de um processo de formação emerge de uma trajetória ligada à análise institucional (Baremblitt, 1996) no percurso de nosso modo de formar-trabalhar. Encontramos, na trajetória da psicologia brasileira, um conjunto de produções que criam um regime de visibilidade para esse fazer institucional (Nascimento; COimbra, 2007; Benevides, 2007; Santos, 2006). Segundo as análises de Neves e Heckter (2007), a formação pode ser pensada como instituição que produz verdades, objetossaberes e modos de subjetivação. Nessa perspectiva, o conhecimento não é um dado a priori, pois produz, num mesmo movimento, sujeito e mundo.

A escrita contribui na análise destes processos institucionais, sendo que René 
Lourau (2004a) e Remi Hess (1988) indicam esse fazer com uma ampla prática diarística. Lourau (2004b) analisa os modos como foram sendo construídos os registros de experiência de pesquisa e de intervenções, bem como as condições de publicação e propõe a noção de texto institucional (TI) - relatório, dissertação, tese - e a escritura extratextual (ET), a qual rompe com a linearidade do texto institucional. O extratexto é uma espécie de escritura diarística e, geralmente, deixado de lado por ser considerado uma fase transitória da própria redação, sendo raramente publicado. Hess (1988) analisou a escrita de um diário na articulação de diferentes dimensões - individual, grupal, organizacional, institucional-, sendo sua preocupação pensar a passagem de um diário intimo, de uma escrita para si, a uma escrita pública, uma escrita para os outros. O Diário Institucional, concebido por Remi Hess em 1976, busca conduzir essa passagem. A técnica consiste da descrição diária dos fatos organizados em torno da relação que se mantém com uma instituição (o trabalho, a relação com a equipe, o processo de uma pesquisa, etc.). A cada dia o registro de algo marcante como um encontro, uma reflexão, uma leitura, etc., considerando a relação deste registro com o objetivo que se dá para este diário. Além da releitura, este diário terá leitores que serão interlocutores de uma análise.

O caráter da circulação da escrita, segundo Hess (1988), acaba por determinar maior precisão do que se escreve, o estabelecimento dos períodos que abrange a experiência escrita, bem como as condições de análise, de reflexão e de teorização do trabalho em questão. Estes elementos apontam a dimensão pedagógica da modalidade de escrita e indicam , segundo o autor, um certo domínio de como se estabelece a relação com o outro. $\mathrm{O}$ autor propõe a seguinte correspondência entre a condição de quem escreve e o tipo de escrita: Pessoal/Diário Íntimo; Interpessoal/Correspondência;

Grupal/Texto datilografado; Social/Texto multigrafado (mimeografado); Público/Texto editado. De um diário íntimo que se restringe ao domínio do próprio autor, passando pela correspondência em que o autor escolhe seu interlocutor, Hess (1988) evidencia os diferentes domínios de difusão do que se escreve, chegando a publicação de um artigo, por exemplo, em que o autor desconhece quem são seus leitores. A organização da escrita ocorre, nessa perspectiva, em função do modo de difusão, sendo que o fato de se datilografar o diário é um facilitador para uma circulação mais ampla. 
Em sua experiência docente, Hess (1988) propõe o diário institucional e a estratégia da passagem progressiva de uma escrita íntima para uma escrita social, a partir de uma de suas experiências docentes universitárias. Ao perceber a dificuldade para desenvolver a escrita acadêmica, em trabalhadores sociais que buscavam a formação em caráter de especialização, o autor pensou em diferentes técnicas para operar a escrita que resultaria numa monografia. As técnicas elaboradas por Hess (1988) foram: a monografia de estabelecimento (descrição do funcionamento do local a que pertencia o trabalhador/estudante); a correspondência institucional com trocas regulares entre duas pessoas que trabalhavam em estabelecimentos com problemas institucionais comparáveis; o romance institucional (história de vida centrada no trabalho, num dado momento, ou sobre uma inserção num estabelecimento). As técnicas visavam a elaboração de uma Análise Institucional sobre o lugar onde se desenvolvia a prática profissional, constituindo ferramentas de análise interna daqueles que buscavam utilizar os conceitos da referida abordagem. A organização da escrita ocorre, nessa perspectiva, em função do modo de difusão, sendo que se tinha como ferramenta de circulação mais ampla do diário o uso da datilografia que possibilitava a cópia e um modo de compartilhar com outros.

Considerando que mais de 20 anos se passaram, desde esta publicação de Remi Hess (1988), evidenciamos as mudanças nas modalidades de escritas e os meios de difusão. Aqui podemos destacar o lugar de ferramentas e de tecnologias de cada época construindo nossas práticas. Hoje temos o e.mail, as listas de discussão, os fóruns, os chats, os blogs, etc., elaborados por uma escrita registrada e disseminada no tempo vivido, sem a espera de uma reprodução em papel e de encontros presenciais para circulação entre indivíduos e mãos. É o envio instantâneo e o recebimento num olhar que tateia rapidamente as palavras na tela. Estas condições trazem outras repercussões para a difusão da escrita e interagem com a noção de Diário Institucional para pensarmos o acesso ao registro e o modo como se escreve no processo de pesquisar e intervir.

A variação do Diário Coletivo em relação ao Diário Institucional de Hess (1988) inicia com a possibilidade de uma escrita compartilhada num tempo instantâneo, com acesso de tudo que é escrito para todos os participantes da lista, conforme possibilita a ferramenta lista de discussão em rede. Essa condição produz a 
expansão da escritura pela interação que convoca de modo permanente pelo uso em internet, bem como pela possibilidade de conectar os participantes do grupo que compartilham um trabalho comum. Cabe destacar que esta lista de discussão, que se torna um diário, é um elemento agenciado nas relações de um grupo de extensão com as políticas públicas juvenis e com a formação em psicologia. Portanto, essa escrita só acontece à medida que o este grupo está no processo de intervenção com alguém que força essa enunciação, ou seja, esse modo de expressão é criado no contágio de experimentações com o processo de formação e com a vida juvenil que vai forçando variações nos modos de escrever-viver uma psicologia que forma e se forma.

Deleuze e Guattari (1995), evidenciam o caráter coletivo e político da linguagem, deixando de ser um sistema de representação, para se tornar uma prática que exprime um regime de linguagem, uma língua própria ao contexto em que se produz. Assim, a língua é composta tanto pelo ordenamento que mantém a constância e reprodução do que se diz, como pela variação que faz surgir novas distinções. A problematização que faz do Diário Coletivo uma questão de pesquisa refere-se a função que essa prática assume no próprio movimento que a produz como elemento processual da intervenção. Analisamos este modo de escrever afirmando o caráter necessariamente coletivo da linguagem, conforme destacam Deleuze e Guattari (1995), cujo discurso indireto referenciado em Mikhail Bakhtin evidencia que a unidade de uma língua é antes de tudo política, pois existem todos os tipos de voz em uma voz e que mesmo uma escrita "individual" carrega muitas vozes.

No âmbito da orientação etnográfica, também, encontramos algumas formulações neste sentido. Clifford (2002) discute as articulações atuais da escrita etnográfica com a obra de Mikhail Bakhtin no que diz respeito a um estilo polifônico ${ }^{2}$ da escrita considerando a abertura do que se escreve para diferentes leituras. O autor destaca a preocupação com o rompimento de uma autoridade monofônica do etnógrafo e suas citações que buscam servir como exemplos ou testemunhos. A busca de uma autoria plural que atribui aos colaboradores não apenas o status de enunciadores independentes, mas de escritores (Clifford, 2002).

Alves (2006) em estudo sobre letramento com uso de ferramentas de informática na Educação, afirma que as implicações teórico-metodológicas de uma proposta de analítica dos agenciamentos, com suas linhas de territorialização e 
desterritorialização, não objetivam enfatizar percursos individuais, mas evidenciar um agenciamento maquínico do desejo, indissociado de um agenciamento coletivo de enunciação sobre a escrita, bem como sobre a oralidade e a informática, entendidas enquanto máquinas sociais. Neste diálogo com Deleuze e Guattari (1997), o autor afirma que os enunciados são remetidos ao agenciamento, maquínico e coletivo de enunciação, não havendo uma face sem a outra pela indissociabilidade dos enunciados com as coisas.

A análise do caráter necessariamente social da enunciação na concepção de um diário, evidencia que o Diário Coletivo pode operar como elemento de um agenciamento coletivo de enunciação, cuja conseqüência é desterritorializar os sujeitos que estariam associados a uma escrita pessoal, grupal, social, pública conforme apresenta Hess (1988). Portanto, podemos dizer que a lista de discussão em análise, não desconsidera o plano de organização com as dimensões de escrita conforme apresenta Hess (1988), bem como as modalidades de texto institucional (TI) e de extratexto ( ET), como destaca Lourau (2000b).O que analisamos como variação e que nos leva a analisar a noção de Diário Coletivo, diz respeito a coexistência dessas dimensões e modalidades com um plano de forças que se produz no entre sujeitos, objetos, formas, constituindo processos relativos aos modos de subjetivação e distribuições moventes na enunciação, conforme destacam Deleuze e Guattari (1997).

Nesta circunstância, escrever é um prolongamento do agenciamento do qual fazemos parte, cujo movimento de dedilhar percorre a duração do processo de formação em psicologia no contexto de extensão. Diferente de digitar, que nos remete a uma datilografia no computador, destacamos que é mais que digitar, dedilhar implica em fazer vibrar com os dedos como num instrumento de cordas (Bueno, 2000). A pragmática do dedilhar, segundo Lazzarotto (2009), indica algo mais que o digitar, pois as letras do teclado são gravadas com vibrações enunciativas de uma prática, cuja matéria de expressão é territorializada no entre relações de uma lista-diário. Nessa direção, pensamos que o movimento de escrita abre possibilidades de constituir grafias inventivas e estéticas para expressar a multiplicidade dos modos de aprender e de praticar psicologia.Um conjunto de matérias de expressão que traçam territórios e vão tomando consistência num conjunto vago e discreto de elementos heterogêneos, reagrupando forças e reorganizando funções para constituir um lugar de passagem e produção de sentido (Deleuze; Guattari, 
1997, 1995). Neste sentido, encontramos línguas menores, como agentes potenciais que fazem a língua maior entrar em um devir minoritário de todos os seus elementos e dimensões, e ao conectarmos e conjugarmos elementos deste devir minoritário, inventamos um devir específico imprevisto e próprio da intervenção.

\section{Movimento III - Cartografando um modo de escrever-intervir}

Como pragmática de uma língua menor nos interessa neste estudo cartografar as variações que são operadas nessas funções, conforme uma política da língua (Deleuze; Guattari, 1995). Passamos a perceber que habitávamos uma pragmática. Ao sermos solicitados para desenvolver uma atividade de extensão acadêmica fomos vivendo o agenciamento da formação em psicologia com as políticas públicas juvenis. Uma face maquinando um currículo, um estágio, um projeto de extensão, professores e estudantes, organizações públicas, teorias, legislações; a outra face enunciando modos de formar-praticar da psicologia com as ressonâncias das políticas juvenis, palavras de ordem nas prescrições do que se deve fazer, palavras passagem de interrogações sobre como fazer ao afetar-se por relações que transbordam o regime de saber psicológico e pedagógico. Em nossas práticas a escrita vai compondo um modo de acolher esse processo de produção coletiva à medida que uma tecnologia, uma metodologia e uma rede de relações macro-micropolítica configuram essa possibilidade.

Neste percurso, conforme propõe Barros (2000), a pesquisa surge da afirmação de um pensamento que se apresenta como problema, como multiplicidade dispersa, onde a pergunta não cessa o movimento interrogante e as respostas se transformam, incessantemente, em novas perguntas. Essa dimensão de pesquisa, segundo a autora, envolve a reflexão sobre a utilização de ferramentas teórico-metodológicas que se expressem por meio de certas formas de interrogação e estratégias analíticas, quando os pesquisadores são cartógrafos e “[ ... ] não se preocupam em transmitir o puro acontecimento, mas incorporam os fatos à própria vida, para comunicá-los como sua própria experiência, deixando na pesquisa seu traço [ . . . ]" (Barros, 2000, p. 33).

Esse modo de escrever cria um regime de visibilidade daquilo que se inventa ao formar-praticar, colocando em análise os efeitos de prescrição em relação ao que se deve fazer e os efeitos de codificação em relação ao que se deve 
saber no sentido abordado por Foucault (2003). Ao operarmos as práticas com políticas públicas juvenis, experimentamos a tensão do fazer profissional que escapa ao saberes prescritos. A feitura desse diário em atividades de extensão compartilhadas num grupo de psicologia e com práticas que se fazem a partir do exercício de análise com jovens e equipes, são condições importantes para compor a pragmática do Diário Coletivo que operamos.

No diálogo com essas análises se produzem nossas questões éticas: ao andar com os dizeres do outro que passagens as palavras carregam que permitem essa escrita? Que compromisso consigo, com o outro e com a vida compartilhada pode ser produzido nesta vizinhança que nos constitui? Deleuze e Parnet (1998) enfatizam que manter a heterogeneidade envolve falar com, escrever com: com o mundo, com uma porção do mundo, com pessoas. Os autores afirmam que a objeção de que se estaria se servindo do outro e depois deixando-o de lado, implica em pensar sobre o que produz uma escrita, pois não se escreve pelo outro ou do outro. Escrevemos daquilo que agenciamos entre um e outro na tentativa de manter o fluxo de um processo onde a vida prolifera. Esta é nossa direção ao analisarmos a constituição do Diário Coletivo no plano de um agenciamento coletivo de enunciação. Ao escrever encontramos entre palavras de ordem componentes de passagem que fazem a linguagem entrar em um devir minoritário conforme analisam Deleuze e Guattari (1995). A palavra de ordem remete aos comandos e a todos os atos que estão ligados aos enunciados por uma obrigação social. Enquanto as palavras de ordem marcam paradas, composições estratificadas, a mesma palavra, tem uma dupla natureza: "é preciso extrair uma da outra transformar as composições de ordem em componentes de passagens." (Deleuze; Guattari, 1995, p. 59) O cartógrafo experimenta, entre as palavras de ordem, a tensão de novas distinções de suas práticas que são expressas nos trajetos e nas intensidades do escrever. Um território existencial está em questão, pois segundo Guattari (1992), a polifonia dos modos de subjetivação envolve uma multiplicidade de maneiras de ser que buscam marcar o tempo, os ritmos de nossas afetações e expressões no percurso das experimentações.

Os modos de criar uma morada para uma desterritorialização na língua, através do Diário Coletivo, afirma tanto outros modos de praticar, como outros modos de formar-se que buscam um estética da existência. A escrita constitui-se 
como modo de manter o movimento de percorrer a prática e perdurá-la em análise, acolhendo o que se vive através de um modo próprio de escrever. Rolnik (1993) evidencia que é assim que se faz o trabalho do pensamento, pois dá para dizer que só se pensa porque se é forçado a fazê-lo. O pensamento, nesta perspectiva, não é fruto da vontade de um sujeito já dado que quer conhecer um objeto já dado. Descobrir sua verdade, ou adquirir o saber onde jaz esta verdade; o pensamento é fruto da violência de uma diferença posta em circuito, e é através do que ele cria que nascem, tanto verdades quanto sujeitos e objetos.

Quando o escrever se dá na eminência de uma prática entre a prescrição e o acontecer, estamos produzindo mais um movimento que compõe uma cartografia. A enunciação de algo que se produz no processo de afetar e ser afetado numa escrita compartilhada. Nessa concepção, não nos centramos na análise do autor, do estudante, do jovem, do técnico ou da equipe, mas nos trajetos dos movimentos que cartografam as práticas que emergem numa enunciação. Nesse sentido, problematizamos a autoria como relação, um estilo a ser criado "entre" signos que circulam, insistem, afetam, e nos forçam a percorrer outras possibilidades de formar-praticar. Formar em psicologia ao mesmo tempo em que essa psicologia se forma; aprender as práticas ao mesmo tempo em que tais práticas estão sendo criadas; estar no encontro com a multiplicidade de um jovem, quando ele é apresentado apenas como efeito de uma justa medida, seja pela sua infração, seja pela situação de abandono.

Ao cartografarmos a pragmática do escrever que produziu este Diário Coletivo, encontramos um modo de expressão que percorre as passagens de sentido dessa experiência, ao invés de prender-se nas constantes de uma linguagem guiada pelo padrão. Como cartógrafos, não buscamos algo já dado, desejamos exatamente o que está sendo inventado, seguindo na abertura para acolher as diferenciações que o pensamento produz com essa experimentação.

Uma vida está em toda parte, em todos os momentos que este ou aquele sujeito vivo atravessa e que esses objetos vivos medem: vida imanente que transporta os acontecimentos ou singularidades que não fazem mais do que se atualizar nos sujeitos e nos objetos. Essa vida indefinida não tem, ela própria, momentos, por mais próximos que estejam uns dos outros, mas apenas entre-tempos, entre-momentos

(Deleuze, 2002, p. 14). 
Nota

1 Conforme artigo 103 do Estatuto da Criança e do Adolescente (ECA), verificada a prática de ato infracional (contravenção penal praticado por sujeitos menores de 18 anos), será determinado pela autoridade competente medidas socioeducativas que, conforme o tipo de infração, envolve desde a advertência até internação com privação de liberdade.).

${ }^{2}$ A partir dos estudos literários e do estilo do romance Bakhtin (2000) situa o monologismo e a polifonia. No monologismo o autor concentra em si mesmo todo processo de criação, coisifica o objeto, as vozes se tornam simples indício de uma coisa, excluindo uma discussão. Já a polifonia se define pela interação de personagens no autor, uma multiplicidade de vozes numa relação dialógica.

\section{Referências}

Alves, E. (2007). Escrita, Tecnologias Digitais e Educação de Jovens e Adultos: uma cartografia inicial de relações entre imagens. Tese de Doutorado, Programa de PósGraduação em Informática na Educação, Universidade Federal do Rio Grande do Sul, Porto Alegre.
Aguiar, K. F.; Rocha, M. L. (2007). Micropolítica e o Exercício da Pesquisa-intervenção: referenciais e dispositivos em análise. Psicologia Ciência e Profissão, Brasília, v. 27, n. $4,648-663$.

Axt, M. (2008). Do Pressuposto Dialógico na Pesquisa: o lugar da multiplicidade na formação (docente) em rede. Informática na Educação: teoria \& prática, Porto Alegre, v. 11, n.1, 92-104.

Axt, M.; Elias, C.R; Martinez, D. F.; Alves, F.; Hartmann, F.; Lazzarotto, G.; Leite, S. M. (2003). Rede de Desassossegos: problematizações acerca de uma experiência pedagógica no ensino superior na interseção com ambientes virtuais. Contrapontos, Itajaí, v. 3, n. 2, 243 254.

Bakhtin, M. (2000) Estética da Criação Verbal. São Paulo: Martins Fontes.

Baremblitt, G. (1996). Compêndio de Análise Institucional e Outras Correntes: teoria e prática. Rio de Janeiro: Rosa dos Tempos.

Benevides, R. B. (2007). Grupo: a afirmação de um simulacro. Porto Alegre: Sulina, Ed. da UFRGS.

Barros, M. E. B. (2000). Procurando Outros Paradigmas Para a Educação. 
Educação e Sociedade, Campinas, v. 21, n. $72,32-42$.

Brasil. (1990) Lei n. 8.069, de 13 de julho de 1990. Dispõe sobre o Estatuto da Criança e do Adolescente e dá outras providências. Diário Oficial da União, Brasília.

Bueno, S. (2000). Minidicionário Brasileiro da Língua Portuguesa. São Paulo: FTD.

Clifford, J. (2002). A Experiência Etnográfica: antropologia e literatura do século XX. Rio de Janeiro: UFRJ.

Coimbra, C. (2001). Operação Rio: o mito das classes perigosas: um estudo sobre a violência urbana, a mídia impressa e os discursos de segurança pública. Rio de Janeiro: Oficina do Autor; Niterói: Intertexto.

Deleuze, G. (2000). Diferença e Repetição. Lisboa: Relógio D’Água.

Deleuze, G. (2002). A Imanência: uma vida... Educação \& Realidade, Porto Alegre, v. 27, n. 2, 11-18.

Deleuze, G.; Guattari, F. (1995) Mil Platôs: capitalismo e esquizofrenia. Volume 2. Rio de Janeiro: Ed. 34.

Deleuze, G.; Guattari, F. (1997). Mil Platôs: capitalismo e esquizofrenia. Volume 4. Rio de Janeiro, Editora 34.

Deleuze, G.; Parnet, C. (1998). Diálogos. São Paulo: Escuta.
Foucault, M. (2003). Mesa-Redonda de 20 de Maio de 1978. In: Foucault, M. Ditos e Escritos IV: estratégia, podersaber. (p. 334-351). Rio de Janeiro: Forense Universitária.

Hess, R. (1998). Uma Técnica de Formação e de Intervenção: o diário institucional (D.I.) Tradução de Ana Lucia Abrahão da Silva e Lucia Cardoso Mourão-Colins. In: Hess, R.; Savoye, A. (Org.). Perspectives de l'analyse institutionnelle. (p. 119138). Paris: Méridiens Klincksieck.

Lazzarotto, G. D. R. (2009). Pragmática de uma Língua Menor na Formação em Psicologia: um diário coletivo e afetações juvenis. Tese de Doutorado. Programa de PósGraduação em Educação em Educação, Faculdade de Educação, Universidade Federal do Rio Grande do Sul, Porto Alegre.

Lourau, R. (2004a). Uma Técnica de Análise de Implicações: B. Malinowski, diário de etnógrafo: 1914 -1918. In: Altoé, S. (Org.). René Lourau: analista em tempo integral. (p. 259-283). São Paulo, Hucitec.

Lourau, R. (2004b). Processamento de Texto. I. In: Altoé, S. (Org.). René Lourau: analista em tempo integral. (p. 199-211). São Paulo, Hucitec. 
Mutti, R. M.V.; Axt, M. (2008). Para uma Posição Enunciativa no Discurso Pedagógico Mediado por Ambientes Virtuais de Aprendizagem. Interface, Botucatu, v. 12, n. 25, 347-361.

Nascimento, M. L.; Coimbra, C. M. B. (2007). Sobreimplicação: práticas de esvaziamento político? In: Nascimento, M. L.; Arantes, E.; Fonseca, T. G. (Org.). Práticas Psi: inventando a vida. (p. 27-36). Niterói-RJ: EDUFF.

Neves, C. A.; Heckert, A. L.C. (2007). Modos de Formar e Modos de Intervir: quando a formação se faz potência de produção de coletivo. In: PINHEIRO, R. et al. (Org.). Trabalho em Equipe sob o Eixo da Integralidade: valores, saberes $\mathrm{e}$ práticas. (p. 145-160). Rio de Janeiro: IMS/UERJ-CEPESCABRASCO.

Rodrigues, H. B. C. (1999). Notas Sobre o Paradigma Institucionalista: preâmbulo político-conceitual às aventuras históricas de "socios" e "esquizos" no Rio de Janeiro. Transversões: periódico de pesquisa do Programa de Pós-Graduação da Escola de Serviço Social da UFRJ. v. 1, n. 1, 169-199.

Rolnik, S. (1993). Pensamento, Corpo e Devir: uma perspectiva ético/estético/política no trabalho acadêmico. Cadernos de Subjetividade. São Paulo, v. 1, n. 2, 241-251.

Santos, N. I. S. (2006). Escola Pública e Comunidade: relações em dobras. Vivência. Natal, v. 31, 62-77.

\section{Gislei Domingas Romanzini Lazzarotto:}

Professora do Departamento de Psicologia Social e Institucional no Instituto de Psicologia da Universidade Federal do Rio Grande Do Sul (UFRGS); Coordenadora do Grupo de Extensão Estação Psi/UFRGS; Pesquisadora Associada do Laboratório de Estudos em Linguagem, Interação e Cognição (LELIC/Faculdade de Educação/UFRGS); Psicóloga; Mestre em Psicologia Social; Doutora em Educação.

E-mail: gislei.ufrgs@gmail.com

Margarete Axt: Professora Titular do Departamento de Estudos Especializados na Faculdade de Educação da UFRGS, dos Programas de Pós-Graduação em Educação (PPGEDU/UFRGS) e em Informática na Educação (PPGIE/ UFRGS); Coordenadora do Laboratório de Estudos em Linguagem, Interação e Cognição (LELIC); Doutora em Linguística.

E-mail: $\underline{\text { maaxt@ufrgs.br }}$ 